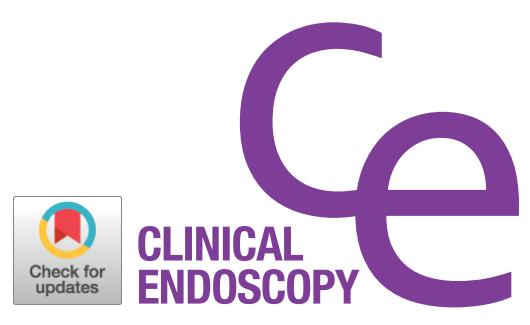

\title{
Use of a Glove-Covered Mouthpiece during Upper Endoscopy to Prevent COVID-19 Transmission
}

\author{
Sho Sasaki ${ }^{1}$, Jun Nishikawa ${ }^{2}$ and Isao Sakaida ${ }^{3}$ \\ ${ }^{1}$ Department of Gastroenterology, Saiseikai Yamaguchi Hospital, ${ }^{2}$ Department of Laboratory Science, Yamaguchi University Graduate \\ School of Medicine, ${ }^{3}$ Department of Gastroenterology and Hepatology, Yamaguchi University Graduate School of Medicine, Yamaguchi, \\ Japan
}

Coronavirus disease of 2019 (COVID-19) caused by SARS$\mathrm{CoV}-2$ has become a global pandemic. All endoscopic procedures should be postponed until the spread of infection has subsided. ${ }^{1}$ However, endoscopy may be necessary to diagnose and treat gastrointestinal cancers and bleeding. Aerosol dispersion due to coughing and retching during upper endoscopic procedures are considered an infection risk. Personal protective equipment (PPE) including face shield, N95 respirator (or surgical mask), cap, isolation gown and disposable gloves is recommended for the medical staffs, whereas patients should be masked until just before endoscopy. ${ }^{2,3}$

We have devised a mouthpiece to prevent aerosol dispersion during endoscopy. This involved cutting the finger off a disposable nitrile glove, followed by cutting the tip of the finger off and then attaching the finger to the mouthpiece for use as the insertion port of the endoscope (Fig. 1A, B). This method was initially applied for overtubes to prevent air leak during endoscopic submucosal dissection. Endoscopic procedure remained feasible, and any aerosolized particles would be trapped by the rubber seal (Fig. 1C). No patients complained of breathlessness or experienced decreased oxygen saturation.

This "glove-covered mouthpiece" may be effective in combination with PPE to prevent transmission of SARS-CoV-2 infection by aerosolization during upper endoscopy.
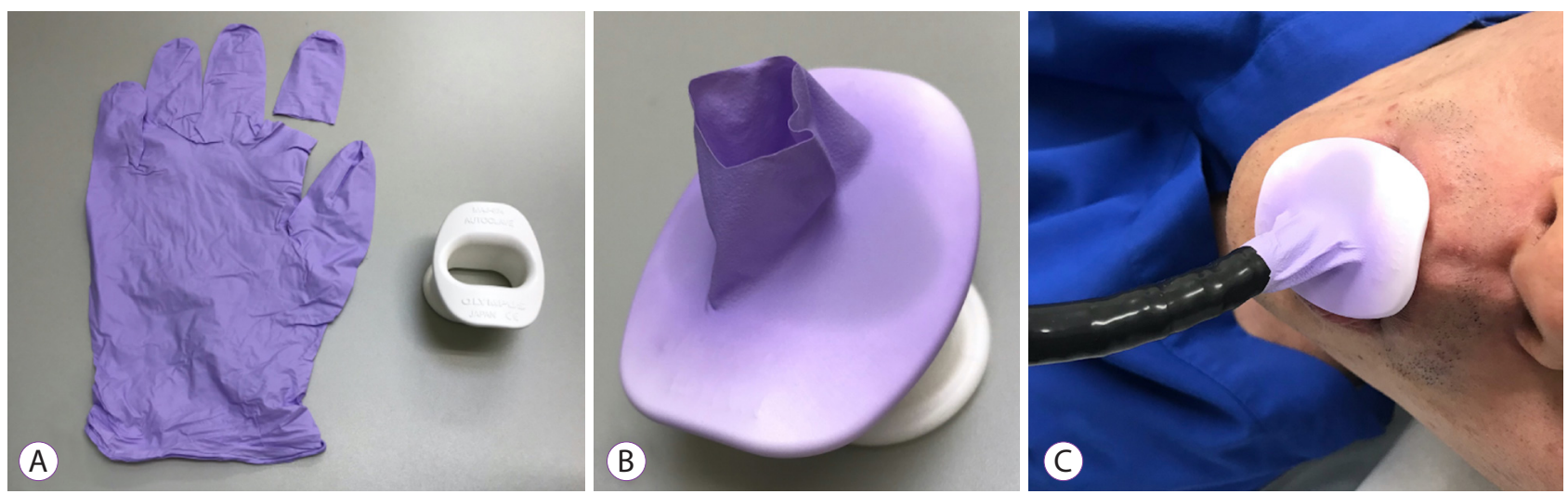

Fig. 1. Glove-covered mouthpiece. (A) The finger of a disposable nitrile glove was first cut off. (B) The tip of the finger was then cut off and the finger was attached to the mouthpiece for use as the insertion port of the endoscope. (C) Any aerosolized particles would be trapped by the rubber seal.

Received: May 5, 2020 Revised: June 3, 2020

Accepted: June 3, 2020

Correspondence: Sho Sasaki

Department of Gastroenterology, Saiseikai Yamaguchi Hospital, Midorimachi 2-11, Yamaguchi 753-8517, Japan

Tel: +81-083-901-6111, Fax: +81-083-921-0714, E-mail: yudaon@yahoo.co.jp

ORCID: https://orcid.org/0000-0003-4043-5562

(c) This is an Open Access article distributed under the terms of the Creative Commons Attribution Non-Commercial License (http://creativecommons.org/licenses/by$\mathrm{nc} / 3.0$ ) which permits unrestricted non-commercial use, distribution, and reproduction in any medium, provided the original work is properly cited. 
Conflicts of Interest

The authors have no potential conflicts of interest.

Funding

None.

Author Contributions

Supervision: Isao Sakaida

Writing-original draft: Sho Sasaki

Writing-review\&editing: Jun Nishikawa

\section{ORCID}

Sho Sasaki:

Jun Nishikawa:

Isao Sakaida: https://orcid.org/0000-0003-4043-5562

https://orcid.org/0000-0002-6695-9754

https://orcid.org/0000-0002-8365-7547

\section{REFERENCES}

1. American Society for Gastrointestinal Endoscopy. Joint gastroenterology society message: COVID-19. Use of personal protective equipment in GI endoscopy [Internet]. Downers Grove (IL): ASGE; c2020 [cited 2020 May 5]. Available from: https://www.asge.org/home/resources/ key-resources/covid-19-asge-updates-for-members/joint-gastroenterology-society-message-covid-19-use-of-personal-protective-equipment-in-gi-endoscopy/.

2. Repici A, Maselli R, Colombo M, et al. Coronavirus (COVID-19) outbreak: what the department of endoscopy should know. Gastrointest Endosc 2020;92:192-197.

3. Chiu PWY, Ng SC, Inoue H, et al. Practice of endoscopy during COVID-19 pandemic: position statements of the Asian Pacific Society for Digestive Endoscopy (APSDE-COVID statements). Gut 2020;69:991-996. 